\title{
Inclusion of biomass burning in WRF-Chem: impact of wildfires on weather forecasts
}

\author{
G. Grell ${ }^{1}$, S. R. Freitas ${ }^{2}$, M. Stuefer ${ }^{3}$, and J. Fast ${ }^{4}$ \\ ${ }^{1}$ Earth Systems Research Laboratory of the National Oceanic and Atmospheric Administration (NOAA), and Cooperative \\ Institute for Research in Environmental Sciences (CIRES), Boulder, Colorado 80305-3337, USA \\ ${ }^{2}$ Center for Weather Forecasting and Climate Studies, INPE, Cachoeira Paulista, Brazil \\ ${ }^{3}$ University of Alaska, Fairbanks, Alaska, USA \\ ${ }^{4}$ Pacific Northwest National Laboratory, Richland, Washington, USA
}

Received: 9 September 2010 - Published in Atmos. Chem. Phys. Discuss.: 16 December 2010

Revised: 15 April 2011 - Accepted: 26 April 2011 - Published: 6 June 2011

\begin{abstract}
A plume rise algorithm for wildfires was included in WRF-Chem, and applied to look at the impact of intense wildfires during the 2004 Alaska wildfire season on weather simulations using model resolutions of $10 \mathrm{~km}$ and $2 \mathrm{~km}$. Biomass burning emissions were estimated using a biomass burning emissions model. In addition, a 1-D, timedependent cloud model was used online in WRF-Chem to estimate injection heights as well as the vertical distribution of the emission rates. It was shown that with the inclusion of the intense wildfires of the 2004 fire season in the model simulations, the interaction of the aerosols with the atmospheric radiation led to significant modifications of vertical profiles of temperature and moisture in cloud-free areas. On the other hand, when clouds were present, the high concentrations of fine aerosol $\left(\mathrm{PM}_{2.5}\right)$ and the resulting large numbers of Cloud Condensation Nuclei $(\mathrm{CCN})$ had a strong impact on clouds and cloud microphysics, with decreased precipitation coverage and precipitation amounts during the first $12 \mathrm{~h}$ of the integration. During the afternoon, storms were of convective nature and appeared significantly stronger, probably as a result of both the interaction of aerosols with radiation (through an increase in CAPE) as well as the interaction with cloud microphysics.
\end{abstract}

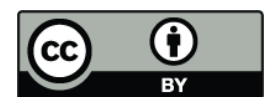

Correspondence to: G. Grell (georg.a.grell@noaa.gov)

\section{Introduction}

It is well known that Alaska wildfires have a strong impact on air pollution from the local up to the hemispheric scale. Although wildfires occur throughout the US, the largest and greatest number of fires occur in Alaska, the southeastern United States, and the West. The climate of Alaska's interior favors annually recurring wildfires due to the available fuels and the common occurrence of thunderstorms. Wildfires burn vast areas almost every summer, and are a significant agent of change in the boreal forest ecosystem. Highly flammable material like dry tundra and leaves and needles at the floor of the boreal forests are well preserved during cold and dry seasons. As a result, both lightning- and humancaused wildfires together burn an average of 400000 hectares annually. Alaska wildfires have gained a lot of attention as fires in remote areas sometimes burn over several months without human suppression (in contrast to fires in most other more populated areas of the globe). Even small Alaska fires may contribute significantly to air pollution.

Extreme fire seasons occurred in 2004 and 2005. The 2004 season was the warmest and third driest summer on record for interior Alaska. By the end of summer 2004, a total of 701 wildfires burned 6.6 million acres $\left(26670 \mathrm{~km}^{2}\right)$ of mostly boreal forest (source of data is from Alaska Interagency Coordination Center, http://fire.ak.blm.gov/aicc.php). The 2004 fire season broke the 1957 record for the most acres burned in one year. The largest fire was the "Boundary Fire" near Fairbanks, which consumed 537627 acres. Particulate matter threatened human health for weeks. For example, high fine particulate matter $\left(\mathrm{PM}_{2.5}\right)$ concentration

Published by Copernicus Publications on behalf of the European Geosciences Union. 
was measured in Fairbanks during the 2004 fire season, when 41 days were reported as unhealthy to hazardous; 16 (of the 41) days were classified as clearly hazardous to human health (source of data is from Fairbanks North Star Borough (FNSB, http://www.co.fairbanks.ak.us/airquality/).

While the impact of fires on air quality has long been realized, much less is known about the impact of fires on weather. Many of the current environmental challenges in weather, climate, and air quality involve strongly coupled systems. It is well accepted that chemical species influence the weather by changing the atmospheric radiation budget as well as through cloud formation. Integrated modeling systems have been developed and used by the atmospheric chemistry research community since the 1990's (Jacobson, 1994, 1997a, b). However, aerosol feedbacks have traditionally been neglected in NWP modeling, due to the necessity to make approximations required by limited computing resources. Although increased attention has recently been given to the impact of chemical constituents (in particular aerosols) on medium-range weather forecasts, this attention is still mostly focused on the interaction of aerosols with atmospheric radiation. Less emphasis is placed on the very complex and highly nonlinear interactions of aerosols with cloud microphysics (for a recent review of state-of-the-art modeling efforts, the reader is referred to Khain, 2009). Inclusion of both feedback processes may either directly improve the forecasts or lead to an indirect improvement through better meteorological data assimilation (Hollingsworth et al., 2008).

The objectives of our study are twofold. First, a wildfire algorithm is added to the community version of the Weather Research and Forecast modeling system (WRF, Skamarock et al., 2005 as it is coupled with Chemistry (WRF-Chem, Grell et al., 2005). Second, because of the capabilities of this modeling system to look at the interaction of aerosols with radiation and microphsyics, we tested this implementation on cloud resolving scales to study the impact of the fires on the simulations of weather. Because of the very intense wildfires, the Alaska 2004 season represented an excellent opportunity to look at these interaction processes. In the following section we will first describe some aspects of WRFChem, in particular the coupling of chemistry, radiation, and cloud microphysics. Next, in Sect. 3, we will explain some aspects of the biomass burning emissions model. Section 4 will discuss the plume rise model that is used to estimate injection heights and final emission rates. Section 5 will give details on the experimental setup. Results will be presented in Sect. 6, with some concluding remarks in Sect. 7.

\section{Model description}

The Weather Research and Forecasting (WRF) model includes various options for dynamic cores and physical parameterizations (Skamarock et al., 2005) so that it can be used to simulate atmospheric processes over a wide range of spatial and temporal scales. WRF-Chem, the chemistry version of the WRF model (Grell et al., 2005), simulates trace gases and particulates interactively with the meteorological fields using several treatments for photochemistry and aerosols developed by the user community. In this study, WRF-Chem V3.2 is used together with the Regional Acid Deposition Model, version 2 (RADM2) photochemical mechanism (Stockwell et al., 1997) coupled with the Modal Aerosol Dynamics Model for Europe (MADE) which includes the Secondary Organic Aerosol Model (SORGAM) (Ackermann et al., 1998; Schell et al., 2001) to simulate aerosol evolution over Alaska. MADE/SORGAM employs a modal approach (Aiken, accumulation, and coarse modes) to represent the aerosol size distribution. An aerosol optical property module (Barnard et al., 2010) was added to WRF-Chem that treats bulk, modal, and sectional aerosol size distribution using a similar methodology for refractive indices and multiple mixing rules. In our study we used the volume averaging mixing rule. Three-dimensional distributions of aerosol optical thickness, single scattering albedo, and asymmetry parameters computed by the aerosol optical property module are passed into the Goddard shortwave radiation scheme to represent the aerosol direct effect (Fast et al., 2006; Barnard et al., 2010). The impact of aerosols on longwave radiation is currently neglected.

The interactions between aerosols and clouds, such as the first and second indirect effects, activation/resuspension, wet scavenging, and aqueous chemistry are described in more detail by Gustafson et al. (2007) and Chapman et al. (2009). While these processes were originally implemented for the MOSAIC aerosol sectional model, they have recently been coupled to MADE/SORGAM in a similar manner by the same authors for the community version of WRFChem (V3.2). To the knowledge of the authors our application is however the first time this setup is applied in a case study.

Following Ghan and Easter (2006), aerosols and gases associated with (i.e. dissolved or suspended in) cloud drops are treated as "cloud borne". Aerosols not associated with any microphysical quantities are treated as "interstitial" as they exist in air between cloud and precipitation particles. In clear air that contains no cloud or precipitation particles, all aerosols are interstitial. The mixing ratios of interstitial and cloud-borne aerosols are treated as separate, fully prognostic species. Aerosols associated with other microphysical categories (i.e. precipitation) are treated diagnostically. The treatment of cloud-aerosol interactions in WRF-Chem is therefore an intermediate representation: more complex than diagnostic methods employed by climate models and yet simpler than fully prognostic approaches. Cloud-aerosol interactions are treated only for liquid clouds and do not treat ice-aerosol interactions; therefore some caution is warranted for conclusions drawn from simulating mixed-phase and ice clouds. 
Aerosol activation is based on the methodology used in the Megacities Impact on Regional and Global Environment (MIRAGE) global aerosol climate model (AbdulRazaak and Ghan, 2000, 2002; Ghan et al., 1997, 2001a, b; Zhang et al., 2002). Bulk hygroscopicity of each size mode, equivalent to $k$ in Petters and Kreidenweis (2007), is based on the volume-weighted average of the hygroscopicity of each aerosol component. Aerosols and trace gases in cloud and raindrops can be modified by aqueous-phase chemical reactions. In WRF-Chem, cloud chemistry uses the bulk approach of Fahey and Pandis (2001) for cloud drops only. As cloud drops are collected by precipitation particles, the cloud-borne aerosols and trace gases are also collected. The cloud-borne aerosols are calculated explicitly, while the cloud-chemistry module provides the fraction of each trace gas that is cloud-borne, or dissolved in cloud water. Aerosols and trace gases that become associated with precipitation within a cloud are assumed to immediately deposit (or fall out) to the surface. Their release back into the atmosphere, due to precipitation evaporation below clouds, is currently not treated. Below-cloud wet removal of trace gases by rain is treated using the approach of Easter et al. (2004), and is limited to several highly soluble gases plus $\mathrm{SO}_{2}$ and $\mathrm{H}_{2} \mathrm{O}_{2}$.

The treatments for activation, resuspension, and wet removal require a cloud microphysics scheme that has a prognostic cloud drop number capability. Therefore, a prognostic treatment of cloud drop number was added to the Lin cloud microphysics scheme as described in Chapman et al. (2009). The prognostic droplet number depends upon advection, droplet loss due to collision/coalescence and collection, droplet loss due to evaporation, and droplet source due to nucleation as described in Ghan et al. (1997). A cloud drop size distribution is assumed that is not affected by aerosols. The parameterization of Liu et al. (2005) was also added to make the autoconversion of cloud drops to rain dependent on the cloud drop number. Therefore, aerosol activation potentially affects rain rate and subsequently the cloud liquid water content depending on whether rain drops become large enough to fall from the cloud. The interaction of clouds and incoming solar radiation was added to WRF-Chem by making the simulated cloud drop number an input parameter to the Goddard shortwave radiation scheme. Thus, the drop number will affect the calculated drop mean radius and cloud optical depth, thereby treating the first indirect effect. Since aerosols have been coupled to only grid-resolved clouds and precipitation, the use of cloud-aerosol interaction in WRFChem is not ideal for grid spacing greater than $\sim 10 \mathrm{~km}$.

\section{The Biomass Burning Emissions Model}

Biomass burning emissions are estimated using the Brazilian Biomass Burning Emissions Model (3BEM). This section summarizes 3BEM as it can be used for WRF-Chem applications. More details can be found in Longo et al. (2010).
An explanation of how we apply it for our case study is given below in Sect. 5 .

3BEM is based on near real-time remote sensing fire products to determine fire emissions and plume rise characteristics (Freitas et al., 2005, 2007; Longo et al., 2010). Fire emissions are updated as they become available and are spatially and temporally distributed according to the fire count locations obtained by remote sensing (mainly from the sensors Advanced Very High Resolution Radiometer (AVHRR, Setzer and Pereira, 1991), Moderate Resolution Imaging Spectroradiometer (MODIS, Giglio et al., 2007), and Geostationary Operational Environmental Satellite (GOES, Prins et al., 1998). Other aerial or ground observations may also be used if available. When using Satellite data, 3BEM employs a hybrid remote sensing fire product to minimize the adverse impact of missing remote sensing observations. The fire product databases may be combined using a filter algorithm to avoid counting the same fire twice, by eliminating additional fires within a circle of a $1-\mathrm{km}$ radius. 3BEM can then merge the fire detection maps with $1-\mathrm{km}$ resolution land use (Belward, 1996; Sestini et al., 2003) and carbon in live vegetation (Olson et al., 2000) datasets to provide the associated emission factor, combustion factor, and carbon density. The emission and combustion factors for each vegetation type are based on the work of Ward et al. (1992) and Andreae and Merlet (2001). The burnt area is estimated by the instantaneous fire size retrieved by remote sensing, when available, or by statistical properties of the scars (see Longo et al. (2010) for more details). Emission rates are estimated using the traditional bottom-up approach (Seiler and Crutzen, 1980). Basically, for each fire pixel detected, the mass of the emitted tracer $(m)$ was calculated by

$m^{[\eta]}=\alpha_{\text {veg }} \beta_{\text {veg }} \xi_{\text {veg }}^{[\eta]} a_{\text {fire. }}$,

which takes into consideration the estimated values for the amount of above-ground biomass $(\alpha)$ available for burning (on a dry mass basis), the combustion factor $(\beta)$ and the emission factor $(\xi)$ for a certain species $[h]$, taking into account the type of vegetation, and the burning area $\left(a_{\text {fire }}\right)$ for each burning event. Although 3BEM was developed for South America its approach should be applicable everywhere. The land cover and carbon density are global datasets and emission factor for boreal forest are reported by the Andreae and Merlet (2001) paper.

\section{Plume rise and online estimation of injection heights}

Biogenic and anthropogenic emissions are, in general, released into the atmosphere with temperatures very close to the ambient air with negligible buoyancy. In this case, in numerical models, they can be treated as surface fluxes. However, biomass burning emits hot gases and particles, which are transported upward by the positive buoyancy generated by the fire. Due to radiative cooling and the efficient heat 
transport by convection, there is a rapid decay of temperature above the burning area. Also, the interaction between the smoke and the environment produces eddies that entrain colder environmental air into the smoke plume, which dilutes the plume and reduces buoyancy. The dominant characteristic is a strong upward flow with moderate temperature excess compared to the ambient air. The final height that is reached by the plume is controlled by the thermodynamic stability of the atmospheric environment and the surface heat flux released from the fire. Additional buoyancy may be gained from latent heat release of condensation, which plays an important role in determining the effective injection height of the plume, that is, its terminal height. In that way, emissions from biomass burning can have a direct and rapid transport into the planetary boundary layer, the free troposphere, and even the stratosphere (e.g., Fromm et al., 2000), developing pyro-convection. This convective scale transport mechanism is simulated by embedding a 1-D time-dependent cloud model (Freitas et al., 2007) with appropriate lower boundary conditions in each column of WRF-Chem (the host model). With this technique, WRF-Chem feeds the plume model with the ambient conditions. As described in the previous section, remote-sensing, aerial, or ground based observations provide fire products and are used in combination with land use (Belward, 1996; Sestini et al., 2003) and carbon fuel (Olson et al., 2000) datasets for selection of appropriate fire properties and to determine in which columns the fires are located, and the plume rise is simulated explicitly. The final height of the plume is then used in the source emission field of the host model to determine the effective injection height where material emitted during the flaming phase would be released and then transported and dispersed by the prevailing winds (Freitas et al., 2006, 2007).

\section{WRF-Chem setup}

\subsection{Experimental domains and initial conditions}

WRF-Chem has the ability to represent both the aerosol direct and indirect effects. While the direct effect may be studied on coarser scales as well as on high resolution, it is more appropriate to study the indirect effect on cloud-resolving scales. The indirect effect involves the microphysical parameterizations and cloud dynamics, which is usually not handled well by coarser scale simulations. For this reason, we chose two 1-way nested domains with regional $(\Delta x=10 \mathrm{~km})$ and cloud resolving $(\Delta x=2 \mathrm{~km})$ resolutions. Figure 1 shows the domain setup.

To provide realistic initial conditions, an 8-day spin-up period was applied with and without biomass burning emissions on domain D1. D1 was initialized on 26 June 2004 and WRF-Chem was run to produce 24-h simulations. The North American Regional Reanalysis (NARR) from the National Centers for Environmental Prediction (NCEP) was

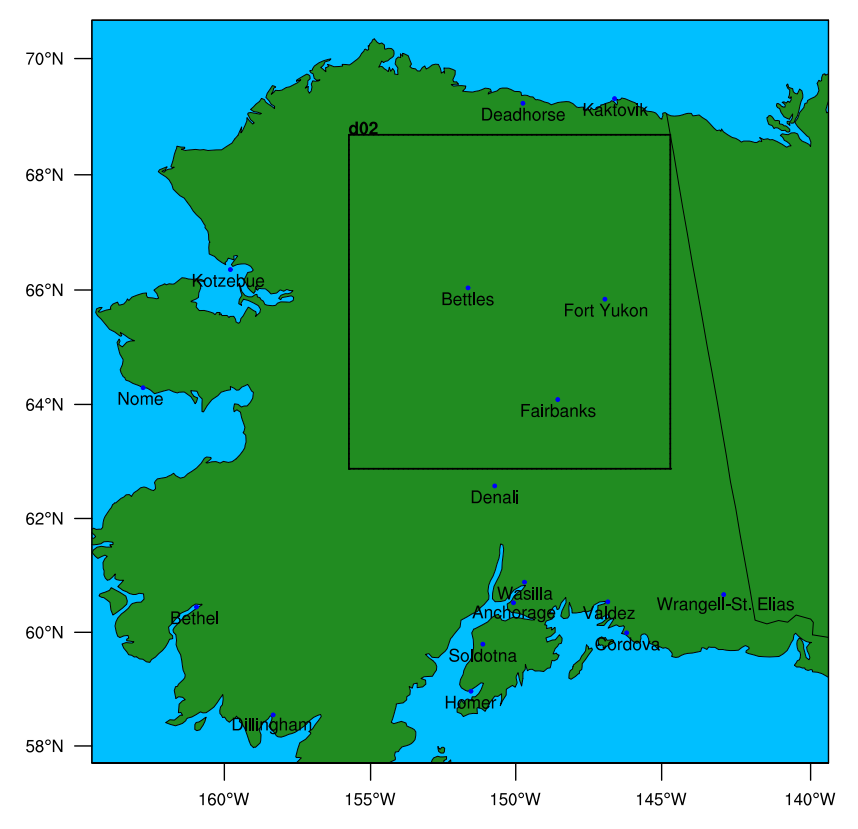

Fig. 1. Model domains used for simulations. D1 had a resolution of $10 \mathrm{~km}$, with $150 \times 150$ grid points and 35 vertical levels; D2 had $336 \times 326$ grid points with $2-\mathrm{km}$ horizontal resolution.

used to provide meteorological initial and boundary conditions. Initial conditions on 26 June for the prognostic gasphase, and aerosol variables are based on those of McKeen et al. (2002). These consist of laterally invariant vertical profiles representing clean, oceanic, midlatitude conditions from measurements collected onboard previous NASAsponsored aircraft missions. Subsequently every $24 \mathrm{~h}$, a new simulation was performed on D1, with new meteorological fields from NARR. The chemistry for all subsequent runs was initialized with the previous 24-h forecast. Biomass burning emissions were provided by 3BEM. Anthropogenic emissions were provided by the "REanalysis of the TROpospheric chemical composition over the past $40 \mathrm{yr}$ " (RETRO, http://retro.enes.org) database, see Freitas et al. (2011) for more details. The identical procedure was repeated for runs without fires (the biomass burning emissions from 3BEM were excluded in this second set of runs).

Physical parameterizations on the regional scale domain include the Mellor Yamada Boundary layer scheme (Janjic, 2002), the NOAH Land Surface model (Chen and Dudhia, 2001), a version of the Grell-Devenyi convection parameterization (Grell and Devenyi, 2002), the Lin et al. (1983) cloud microphysics scheme, coupled to the model aerosol parameterization and modified to include second moment effects (see discussion above). The 24-h simulations starting at 00:00 UTC, 2 July 2004, provided the chemical initial fields for the WRF-Chem simulations described below. 
(a)

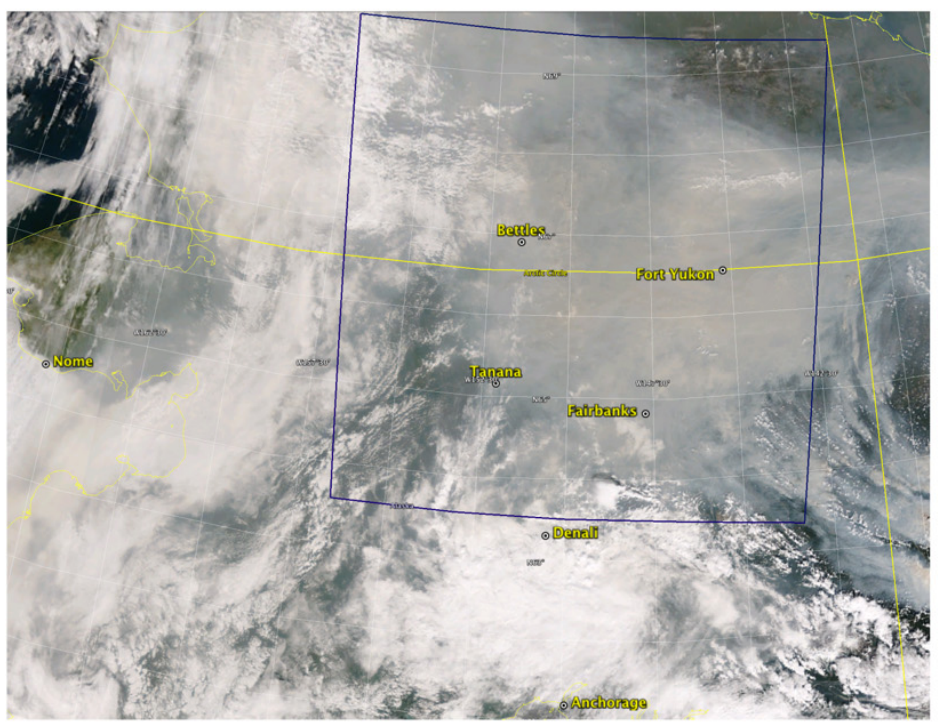

(b)

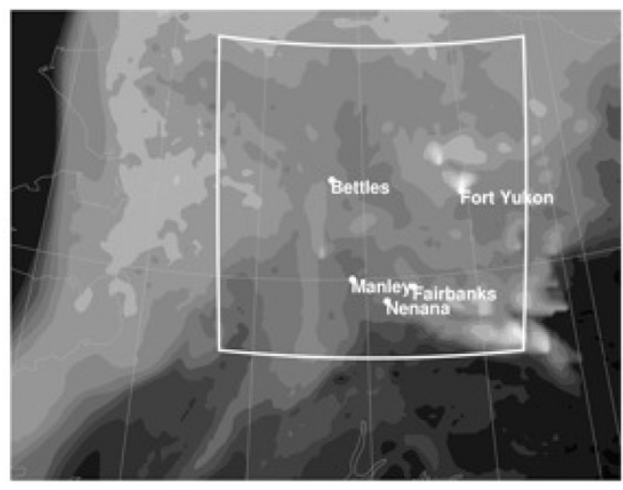

Fig. 2. MODIS Satellite picture over Alaska from 3 July, 21:23 UC (a) and model predicted integrated and vertically averaged PM 2.5 (b) for 3 July, 21:00 UTC. Indicated is also the domain boundary for the cloud resolving nest.

(a)

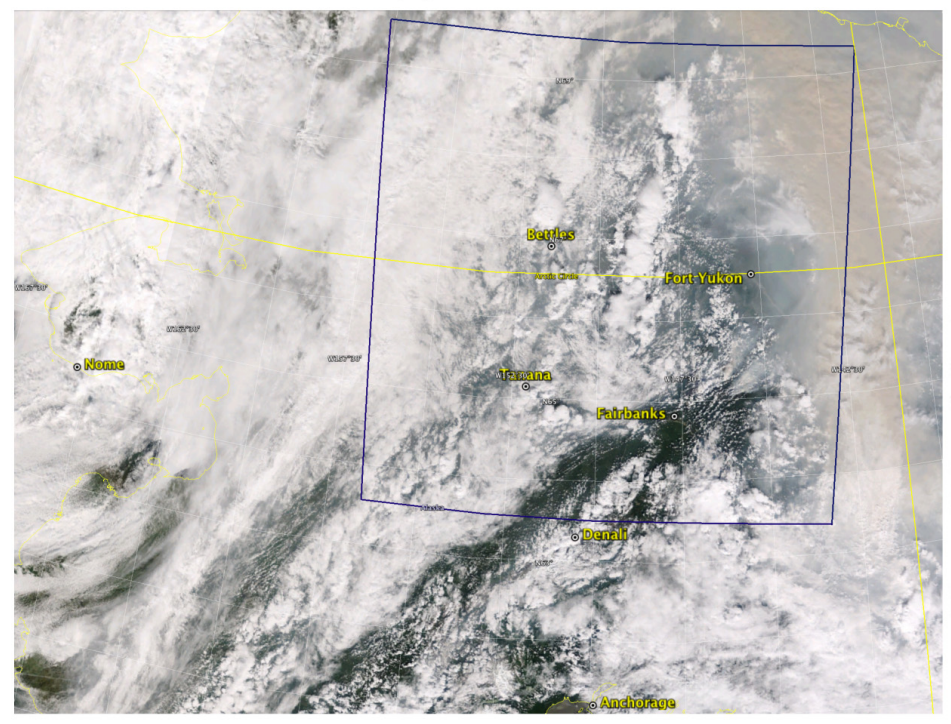

(b)

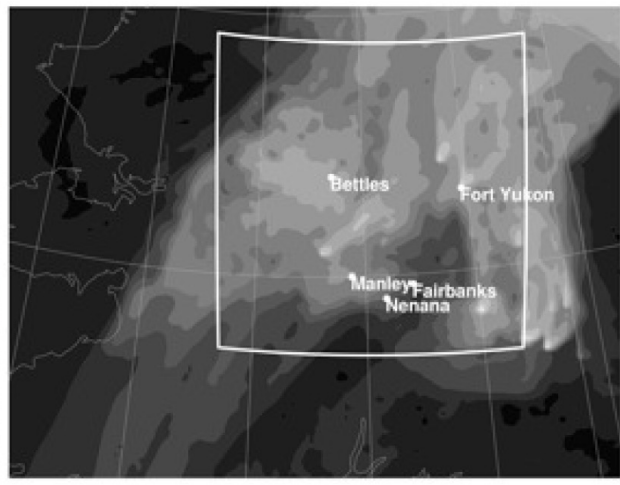

Fig. 3. MODIS Satellite picture over Alaska from 4 July, 22:23 UC (a) and model predicted integrated and vertically averaged PM 2.5 (b) for 5 July, 00:00 UTC. Indicated is also the domain boundary for the cloud resolving nest.

\subsection{The cloud resolving domain}

Initial meteorological fields for domain D2 also came from NARR. However, higher resolution terrain was added. The location and size of the domain was chosen to cover a large part of the area occupied with smoke, and to include the Fairbanks rawinsonde site. Additionally the integration period (00:00 UTC 3 July to 00:00 UTC 5 July) includes sunny and dry weather periods as well as convectively active wet periods. Boundary conditions for both meteorology and chemistry come from domain D1 (3-hourly). The chemical fields were also initialized from domain D1, to make use of the 10-day spin up period. Physical parameterizations as well as chemical modules were identical to the larger domain, except that no convective parameterization was used for the integration over D1. 
(a)

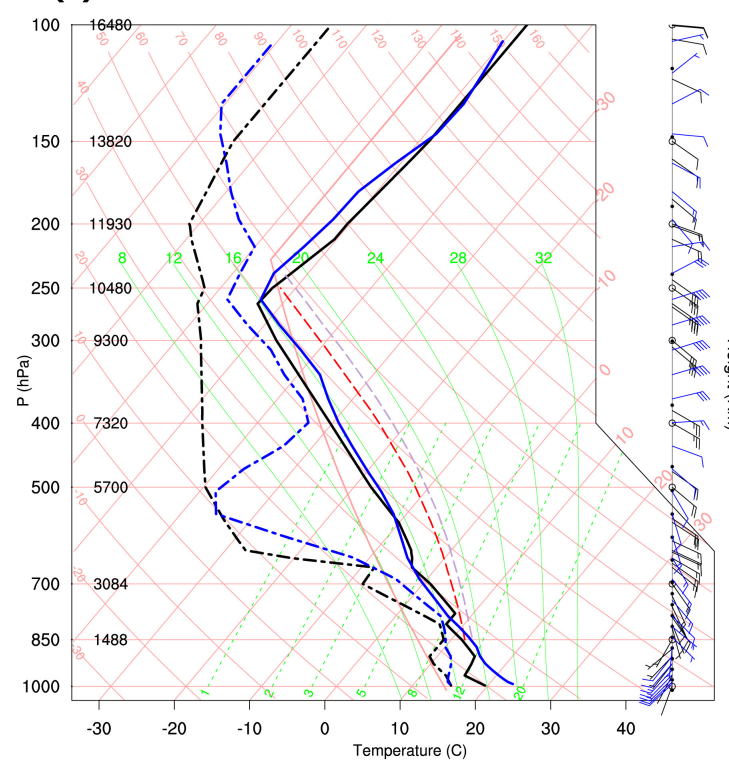

(b)

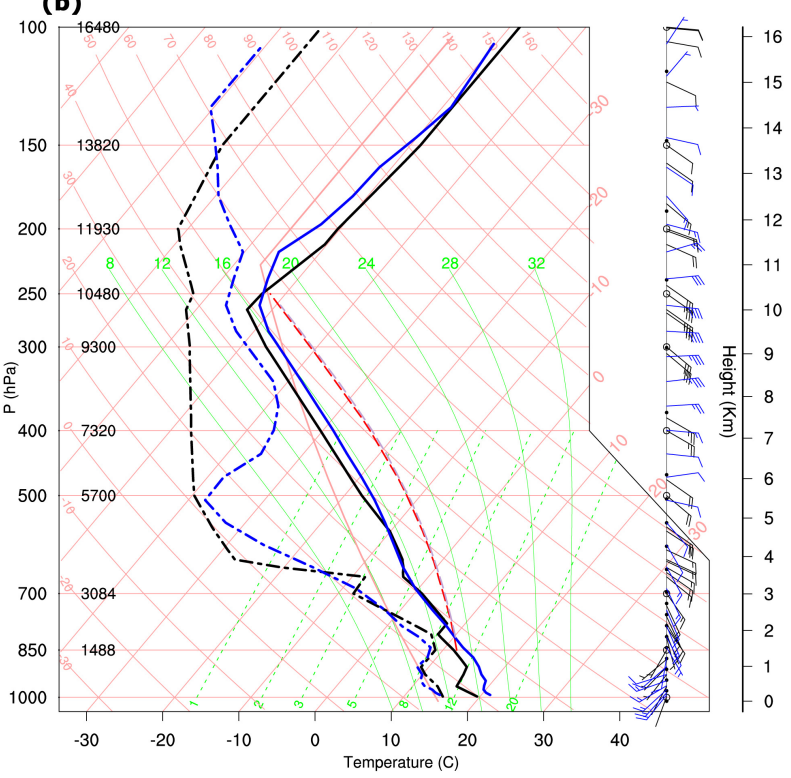

Fig. 4. Observed (black) and predicted (blue) sounding for Fairbanks, Alaska, on 4 July, 00:00 UTC. Shown is temperature (solid), dew points (dashed-dotted) and wind barbs for runs without fires (a) and runs with fires (b). A moist adiabat based on a mixed parcel for the lowerst $100 \mathrm{mb}$ of the observed (simulated) sounding is dashed in red (magenta).
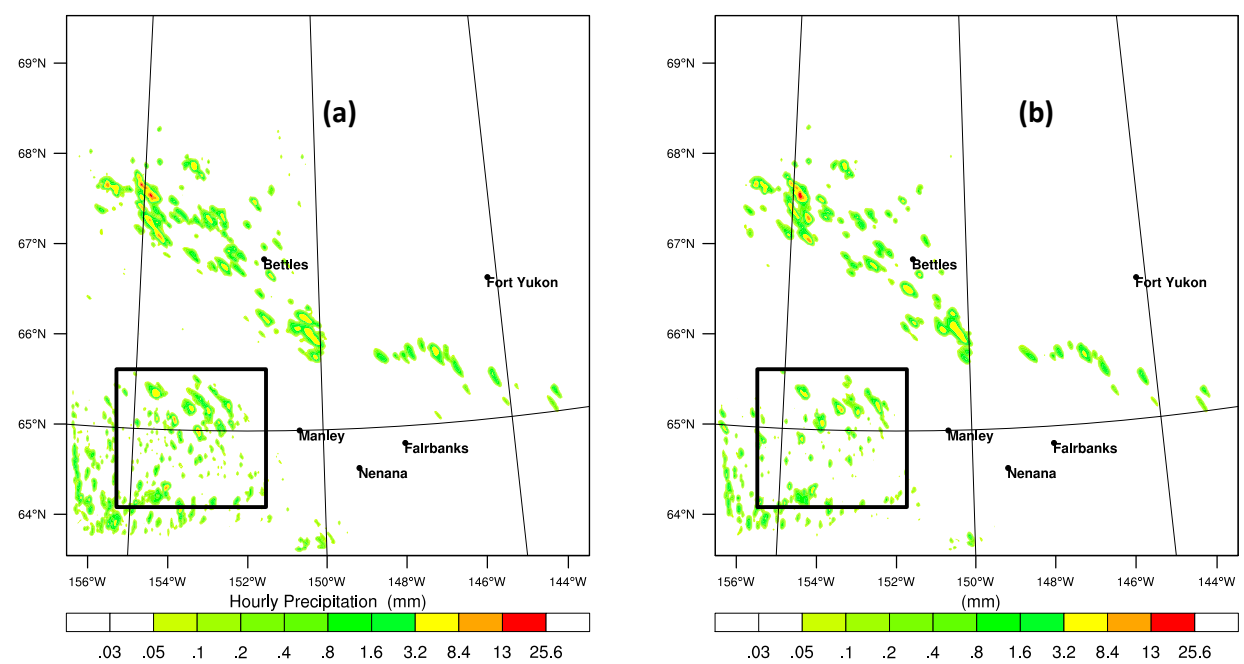

Fig. 5. Hourly accumulated precipitation at 3 July, 03:00 UTC, without fires (a) and with fires (b). Shown is also Box A, over which averages shown in Fig. 6 are calcuated.

\subsection{Initialization of fires}

The biomass burning emissions module described in Sect. 3 can make use of information from many different sources. While the most likely source for real-time applications comes from satellite data, we had additional information to run the model in retrospective mode. For our studies, the daily fire size was obtained from the Alaska Interagency Coordination Center (AICC).
AICC is the focal point for Alaska wild land fire management and maintains a geographic information system with fire burned area updated multiple times a day during the fire season. The AICC fire area estimates are derived from personnel in the field and from aircraft observations. For the following case study we used the AICC database for 2004, which contains information for all fires observed during the season, start and end dates and total burned areas of each fire. In absence of daily data of the actual fire size, we assumed a 


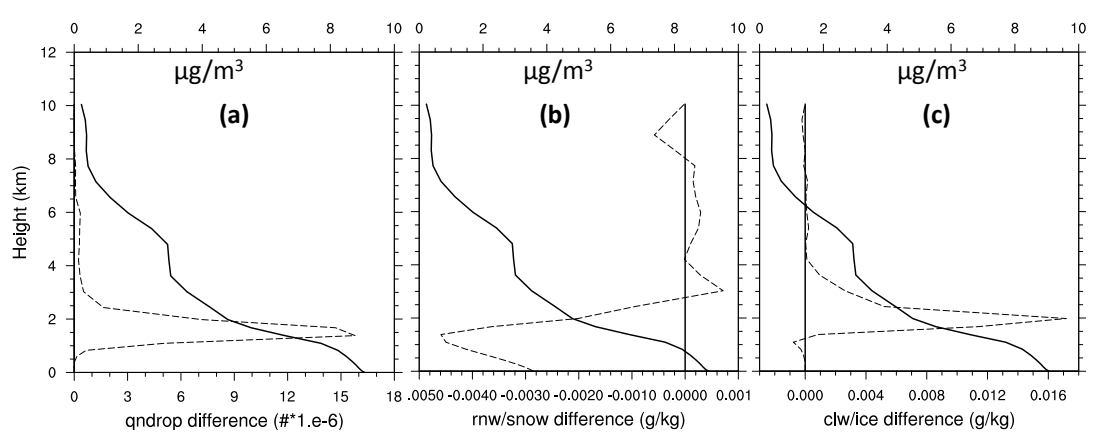

Fig. 6. Hydrometeor properties averaged over Box A (shown in Fig. 5). Displayed is the difference (dashed line) in droplet number density (a), the sum of rain water, snow, and graupel mixing ratio (b) and the sum of cloud water and ice mixing ratio (c) for the run with fires minus the run withoput fires. Shown also on all 3 panels is the total $\mathrm{PM}_{2.5}$ concentration (solid line) for the run with fires.
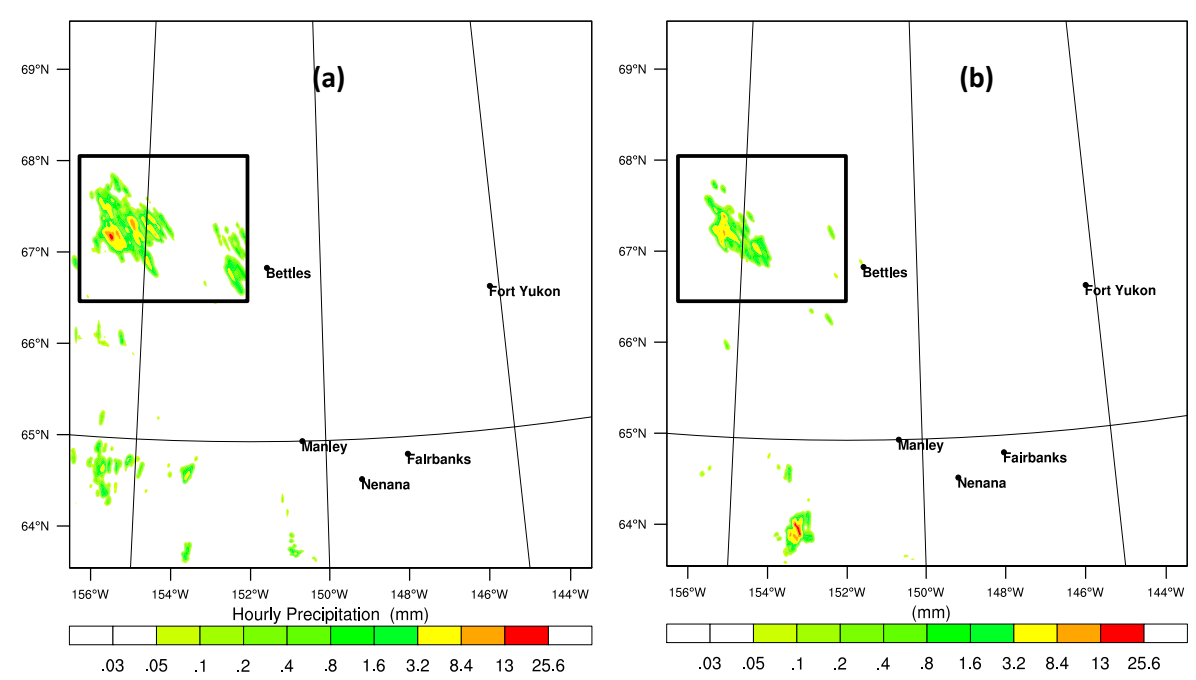

Fig. 7. Hourly precipitation at 3 July, 12:00 UTC, without fires (a) and with fires (b). Shown also is Box B, over which averages shown in Fig. 8 are calculated.

linear fire spread throughout the lifetime of a fire. The fire location and area data were compared with good accuracy with thermal anomaly data using the MOD14 algorithm (Justice et al., 2002) and MODIS satellite data made available through the Geographic Information Network of Alaska (GINA) of the University of Alaska Fairbanks.

\section{Results}

MODIS Satellite pictures over Alaska from 21:23 UTC 3 July and the model predicted, integrated and vertically averaged $\mathrm{PM}_{2.5}$ for 21:00 UTC 3 July are shown in Fig. 2. The domain boundary for the cloud-resolving nest, D2, is also indicated. Simulated injection heights from many fires were limited to $2-3 \mathrm{~km}$, except for a fire location to the southeast of Fairbanks where injection heights reached the middle troposphere. High concentrations of smoke were simulated over D2, with highest concentrations southeast of Fairbanks and north of Fort Yukon. The model also correctly simulated the smoke in the western part of the domain, which must have originated from the Alaska fires, since no boundary conditions (other than background conditions) were available for the large domain (D1). Smoke must have been transported from Alaska out over the Gulf of Alaska, before being returned in shifting wind conditions. Note that at the same time there were also large fires in Canada, outside of D1, leading to a significant underprediction of aerosol concentrations in the eastern part of D1, but outside domain D2.

$24 \mathrm{~h}$ later (Fig. 3), the weather situation changed significantly with increased convection and rain over large parts of the domain and southwesterlies bringing smoke-free and much cleaner air to Fairbanks.

While the main goal of this paper is not to verify against observations, it is gratifying to be able to show some improvement in weather simulations. This should be expected, since in our cases a very strong signal was provided by the 


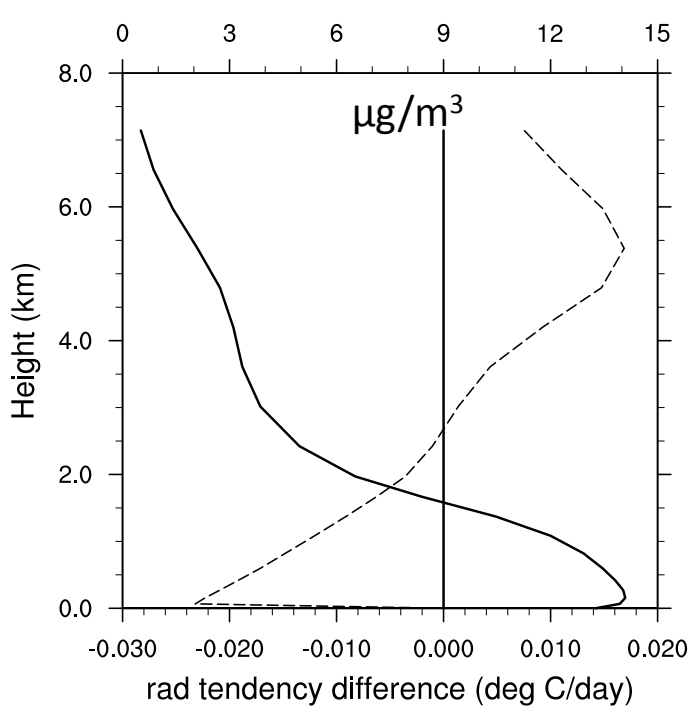

Fig. 8. Radiative temperature tendency differences (dashed line) averaged over Box B (shown in Fig. 7) for the run with fires minus the run without fires. the solidl ine is the total averaged $\mathrm{PM}_{2.5}$ concentration for the runs with fires.

intense and large fires of the 2004 fire season. While it could usually be difficult to predict aerosol concentrations with enough accuracy to show an improvement in weather prediction, our study is an exception. This is shown in Fig. 4, which compares the model predicted and observed soundings for 00:00 UTC 4 July for the runs with and without fires (cloud resolving simulations). The runs with fires produced much closer agreement with observations. Boundary Layer temperatures were cooler, the air was dryer, Convective Available Potential Energy (CAPE) was almost identical to observations for the runs with fires. In general, the simulated soundings representing the observed atmosphere were in much closer agreement in the lowest $5 \mathrm{~km}$ of the atmosphere. We also compared soundings at 12:00 UTC 4 July and at 00:00 UTC 5 July. While the 12:00 UTC soundings were almost identical for the two simulations (very little impact by the fires), the 00:00 UTC soundings 5 July also showed some improvement, indicating that the radiative impact was probably the largest positive effect on the simulations. However, since some precipitating clouds were in the general area, the aerosol indirect effects may also have contributed to the improved simulation . The radiative impact includes the direct interaction of aerosols with radiation through scattering and absorption as well as the semi-direct effect (radiative changes through differences in cloud cover).

Next we focus on comparing the cloud resolving simulations with and without the effect of the wildfires. Fig. 5 shows hourly precipitation for the hour ending at 03:00 UTC 3 July for runs with and without fire, early in the forecast and over domain D2. At this time most of the fire impacts
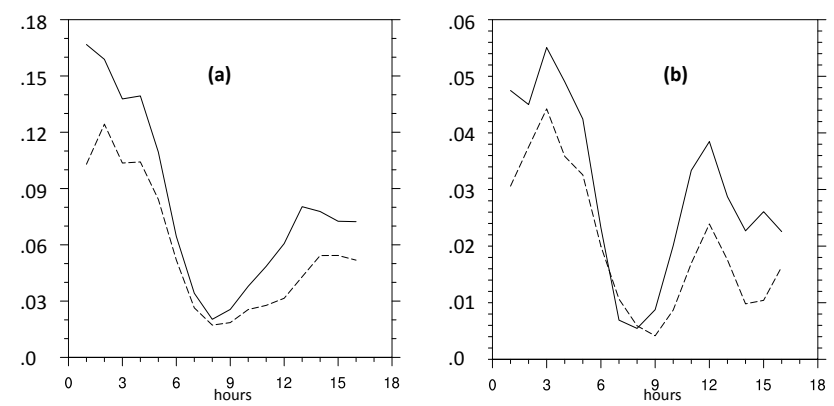

Fig. 9. Fractional coverage (a) of grid points with precipitation and domain averaged precipitation rate in $\mathrm{mm} \mathrm{h}^{-1}$ (b) over area D2 for the first $18 \mathrm{~h}$ of the simulation. the solid line indicated run without fires, dashed line is for the runs with fires. The horizontal axis is the simulation time in hours.
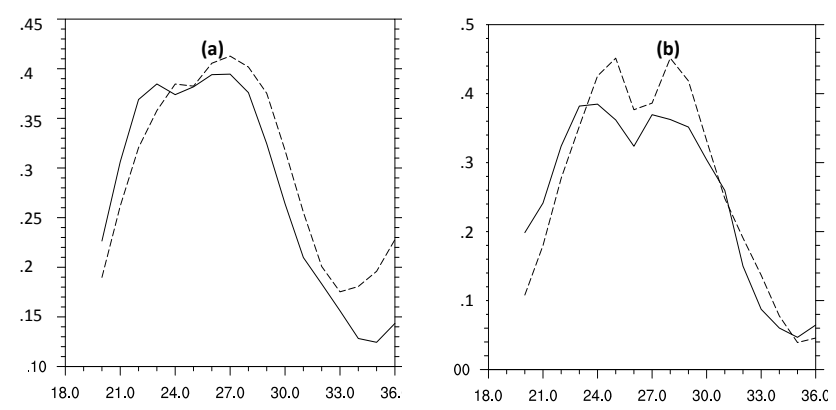

Fig. 10. Fractional coverage (a) of grid points with precipitation and domain averaged precipitation rate in $\mathrm{mm} \mathrm{h}^{-1}$ (b) over area D2 from 3 July, 18:00 UTC, 4 July. The solid line indicates run without fires, dashed line is for the runs with fires. The horizontal axis is the simulation time in hours.

were caused by interactions of the aerosols with cloud microphysics. Radiative impacts were still small (see also discussion below and Fig. 8). High aerosol concentrations caused by the wildfires and the responding high numbers of Cloud Condensation Nuclei (CCN) led to an increase in the cloudwater mixing ratio, a decrease in the rainwater mixing ratio, and an in increase in droplet numbers. This can be seen in Fig. 6, which displays mixing ratios of hydrometeors averaged over Box A. Box A was chosen to cover an area representative of the rainfall differences in the southwest of domain D2 at 03:00 UTC (the location of Box A can be seen in Fig. 5). The droplet number density is sharply increased, as is the sum of cloud water and ice-mixing ratio, while rainwater-, snow-, and graupel-mixing ratios are decreased. This behaviour is expected, since the air is very polluted and the non-convective precipitating clouds are low level (see also Khain et al., 2008; Khain, 2009; Han, 2010). Figure 6 also shows the averaged total $\mathrm{PM}_{2.5}$ concentration (solid line) for the run with fires. Note also that the increase in the droplet number density and the decrease in the rain/snow-mixing ratio peak at the same level (approximately 

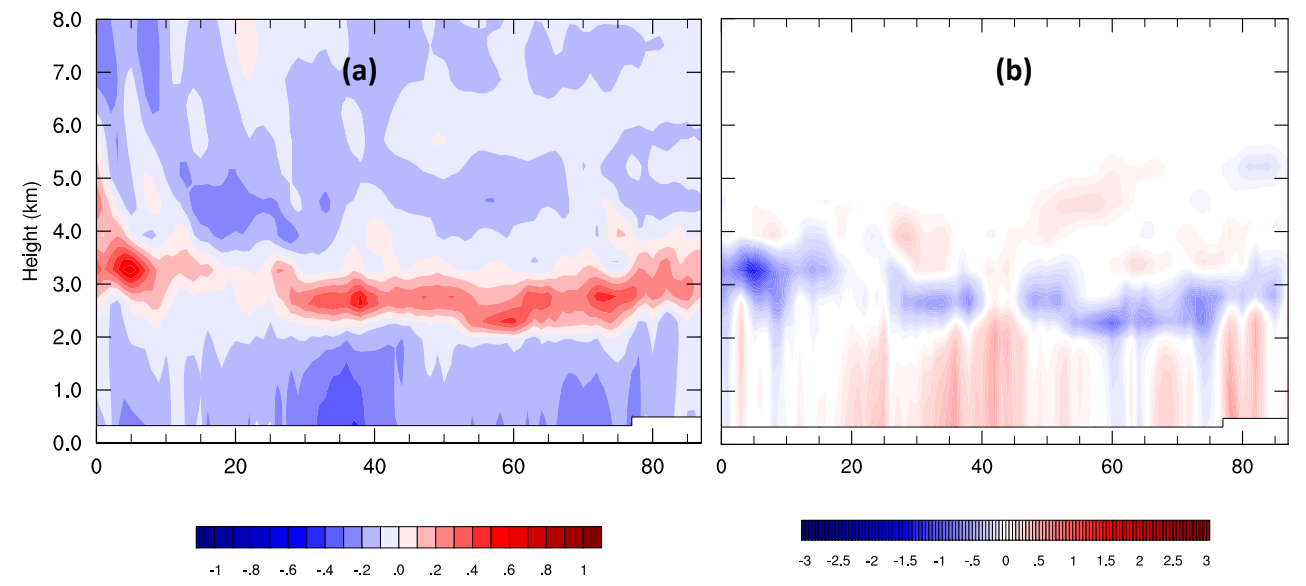

Fig. 11. Temperature (a) differences in ${ }^{\circ} \mathrm{C}$ and water vapor micing ratio (b) differences $\left(\mathrm{g} \mathrm{kg}^{-1}\right)$ from the runs with fires minus the run without fires for cross section A (shown in Fig. 13a) at 22:00 UTC, 3 July 2004. Field are averaged along a line that extends 5 grid points into an out of the cross section.

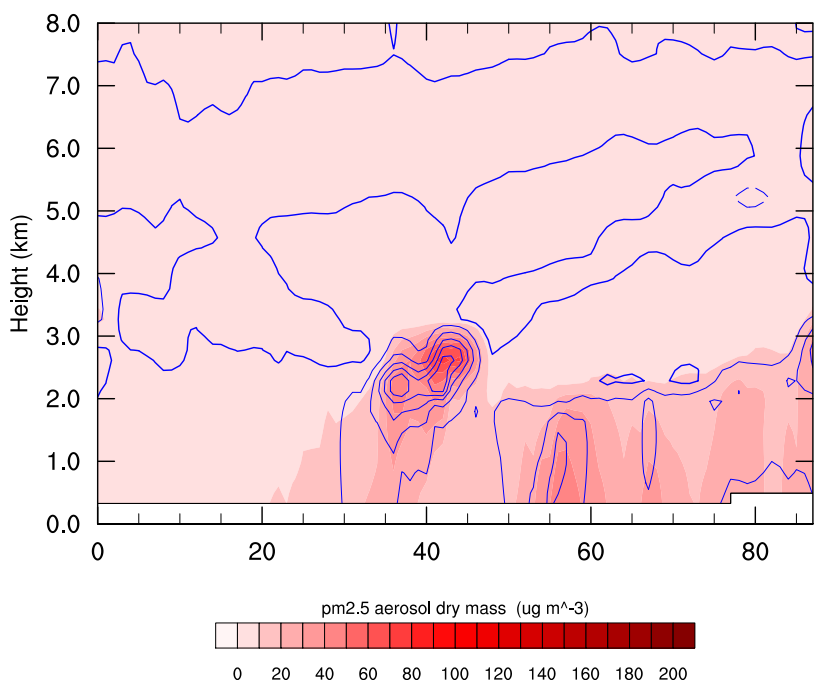

Fig. 12. Radiative temperature tendency differences in ${ }^{\circ} \mathrm{C}$ (blue contours from $-{ }^{\circ} \mathrm{C}$ (dashed) to $+3{ }^{\circ} \mathrm{C}$ in half degree intervals) overlayed with $\mathrm{PM}_{2.5}$ concentrations (in red) for cross section $\mathrm{A}$ (shown in Fig. 13a) at 22:00 UTC, 3 July 2004. Fields are averaged along a line that extends 5 grid points into and out of the cross section.

at $1.5 \mathrm{~km}$ above the surface), while the increase in cloud water/ice mixing ratio peaks somewhat higher at about $2 \mathrm{~km}$ above the surface. This is probably the result of transport from interactions that took place upstream of Box A. The highest $\mathrm{PM}_{2.5}$ concentrations are found near the surface, with a second maximum at about $5 \mathrm{~km}$. This second maximum $\mathrm{PM}_{2.5}$ appeared to be related to the smoke entering D2 from the southwest.

By 12:00 UTC results were still qualitatively very similar, as shown in Fig. 7. There was less precipitation in the simulations that included the effects of fires. Although shortwave radiation was still active in Alaska at this hour, its impact was small and differences in radiative tendencies may have also been caused by differences in cloud fields. Figure 8 shows the averaged temperature tendency differences from the atmospheric radiation routine for Box B as well as the averaged fine aerosol concentrations $\left(\mathrm{PM}_{2.5}\right)$. Differences in tendencies are in general very small, and should not be the reason for the difference in predicted precipitation tendencies.

The domain averaged (D2) precipitation rates as well as fractional coverage of precipitating grid points over the first $18 \mathrm{~h}$ of the simulation are shown in Fig. 9 and indicate consistently lower precipitation as well as less coverage when the impact of fires was considered. This was expected because of the non-convective nature of most clouds in addition to the extremely high aerosol concentrations in the smoky areas, resulting in large $\mathrm{CCN}$ numbers, high droplet concentrations, small droplets and less conversion to rain.

During the daytime, results qualitatively changed drastically. Clouds become very convective, storms became more intense, and precipitation became more widespread in the runs with fires. This can be seen in Fig. 10, which shows the fractional coverage of grid points with precipitation and domain averaged precipitation rates over area D2 during the second $18 \mathrm{~h}$ of the simulation. The largest domain-averaged differences were in the late afternoon and evening when convective activity was strongest Note that domain D2 still includes areas with stable shallower clouds and stable precipitation. Towards the morning, the results almost flipped again, although the fractional coverage remained higher for the runs that included the effects of fires. We attribute the muchincreased precipitation to both the radiative feedback as well as the microphysical feedback. This is explained further in the following paragraphs.

In the eastern part of the domain it may be most straightforward to try to separate these effects, since before 00:00 UTC 4 July, large parts of the domain were cloud-free. 


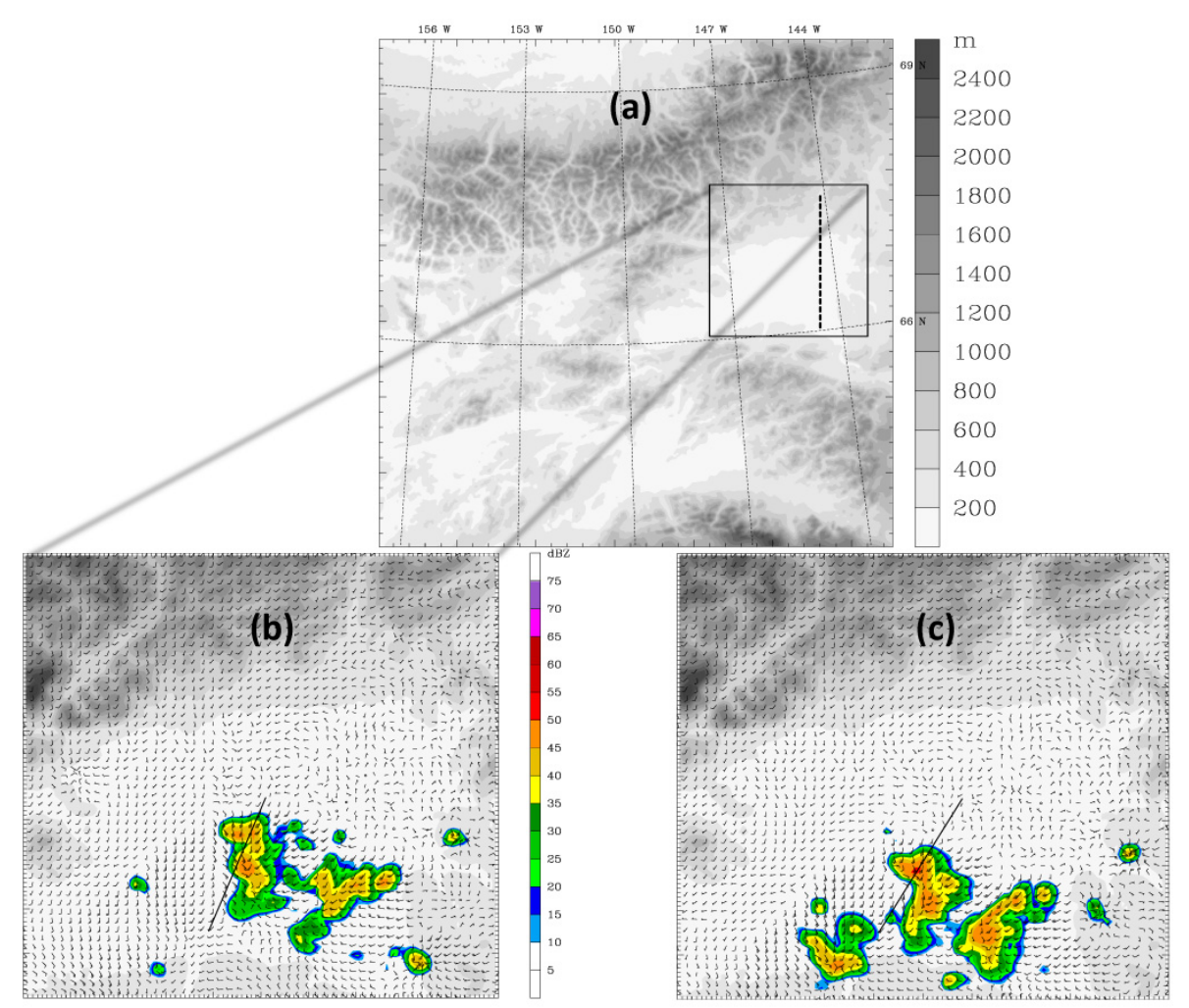

Fig. 13. Maximum dbz for storms at around 02:00 UTC, 4 July without (b) and with (c) fires in the eastern part of the domain (a). Terrain is shaded. Cross section A is shown in (a) with dashed line, cross section B is marked in (b) and (c) with a solid line.

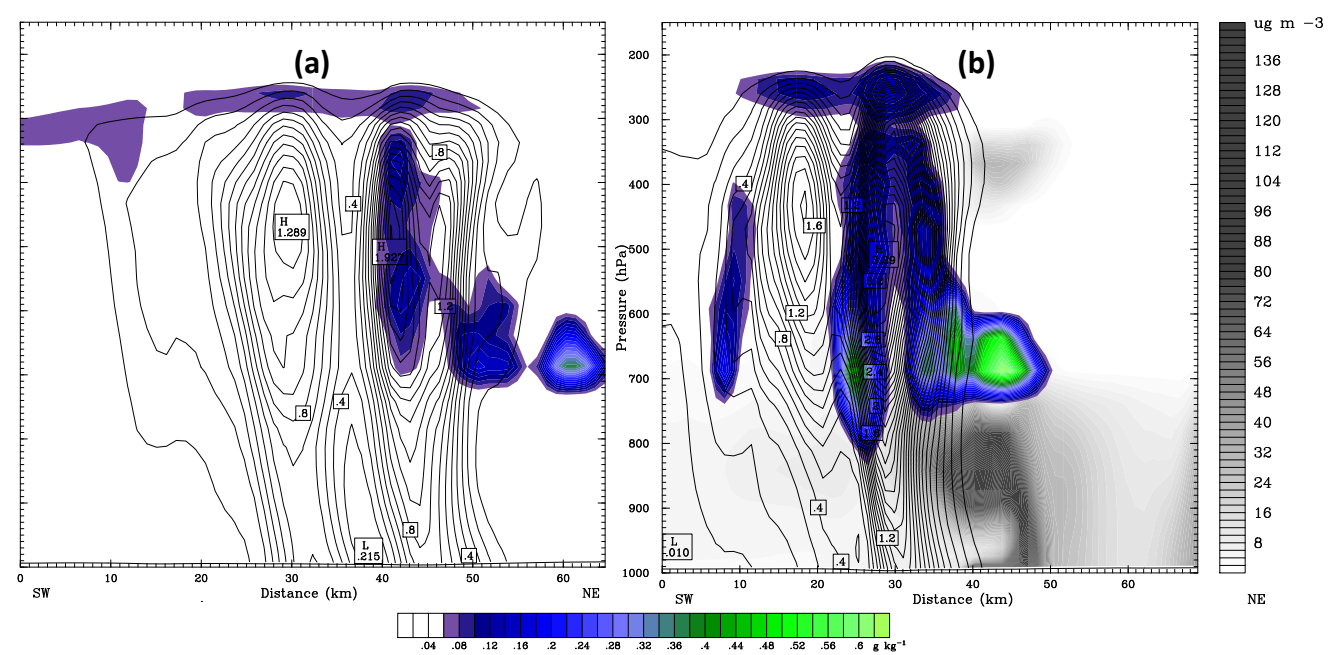

Fig. 14. Cloudwater/ice mising ratio (color), rain water, snwo and graupel mixing ratio (black lines) and $\mathrm{PM}_{2.5}$ concentrations (gray shades) for cross section B (shown in Fig. 13) and runs without (a) and with (b) fires. Fields are averaged along a line that extends 5 grid points into and out of the cross section.

Figure 11 shows temperature and dewpoint differences for cross section A (defined in Fig. 13) before any precipitation formed (22:00 UTC 3 July). Temperatures were significantly higher, especially near the top of the boundary layer. Dewpoints were higher in the boundary layer, but significantly lower just above. This is caused by a shallower boundary layer in the runs with fires. Aerosols appear to heat the atmosphere strongest at the top of the boundary layer, leading to a more stable and shallower PBL. Since the dewpoints were also somewhat higher in the lowest levels, CAPE was 


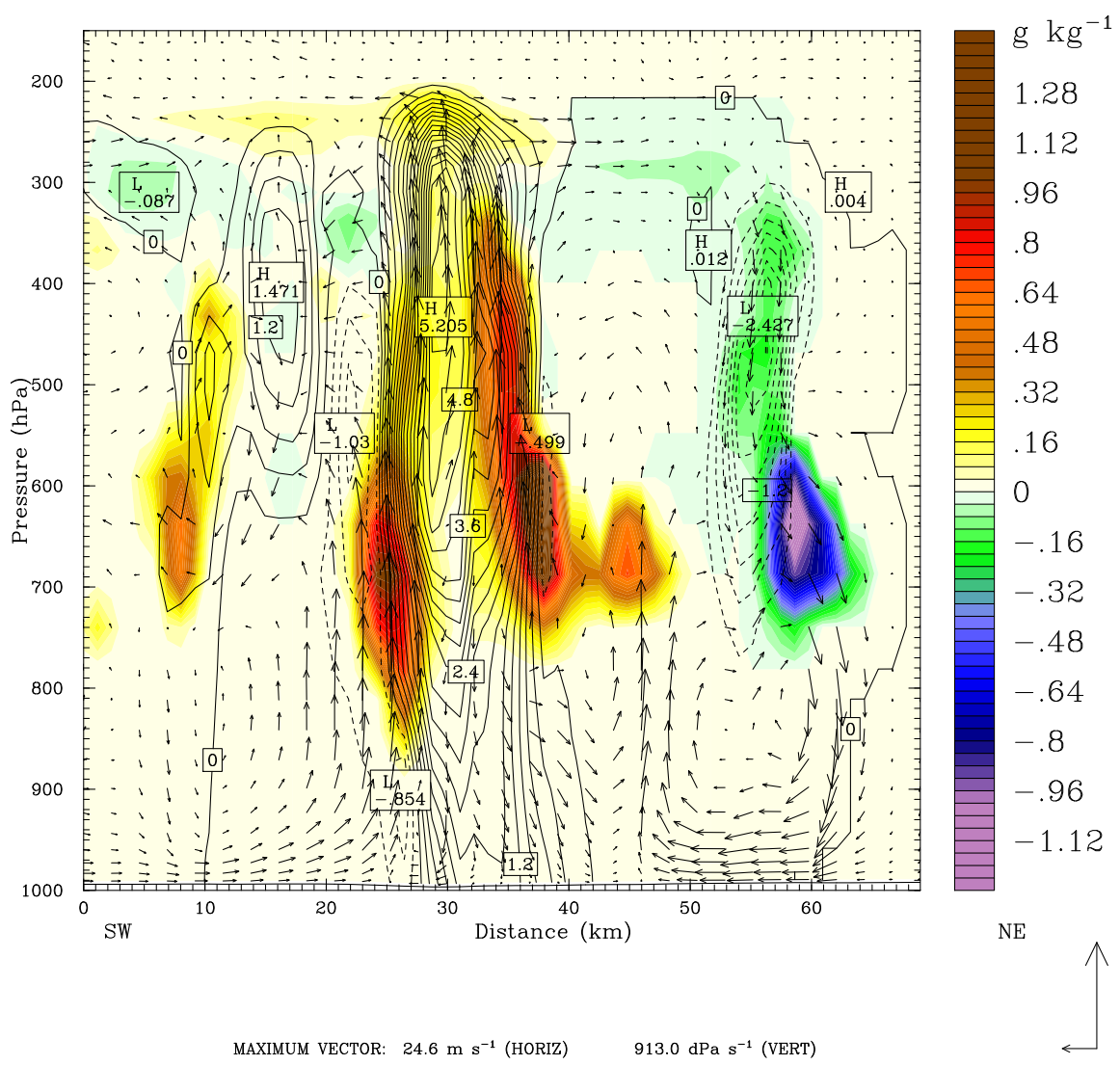

Fig. 15. Differences fields (runs with fires - runs without fires) of the sum of couldwater and ice mixing ratio (color), the sum of rain water, snow and graupel mixing ratios (black lines), and winds in the cross section (arrows) for cross section B (shown in Fig. 13) and runs without (a) and with (b) fires. Fields are averaged along a line that extends 5 grid points into and out of the cross section.

increased slightly. This holds for most of the area in the northeastern cloud-free region of the domain. Figure 12 displays the temperature tendency differences from the atmospheric radiation parameterization for the 2 runs, showing that the increase in temperature is well collocated with intense $\mathrm{PM}_{2.5}$ plumes. Biomass burning has large black carbon emissions, which leads to a lot of absorption in addition to decreased shortwave radiation near the surface.

Next we will look at differences in some convective storms in the same area a few hours later. Storms formed in approximately the same positions at the same time (00:00 UTC 4 July). Figure 13 displays simulated echo intensity (maximum DBZ) for the runs with and without fires indicating the location of the storms in domain D2 and about 2 hours after they had formed (02:00 UTC 4 July). From this figure it can be seen that the intensity of the storms in the run with fires was significantly stronger. The hydrometeor fields and the $\mathrm{PM}_{2.5}$ concentrations in cross section $\mathrm{B}$ for both runs are shown in Fig. 14; for this cross section the fields were averaged along a line that extended 5 points into and out of the cross section. The resulting differences in hydrometeor fields and winds in the cross section are shown in Fig. 15.

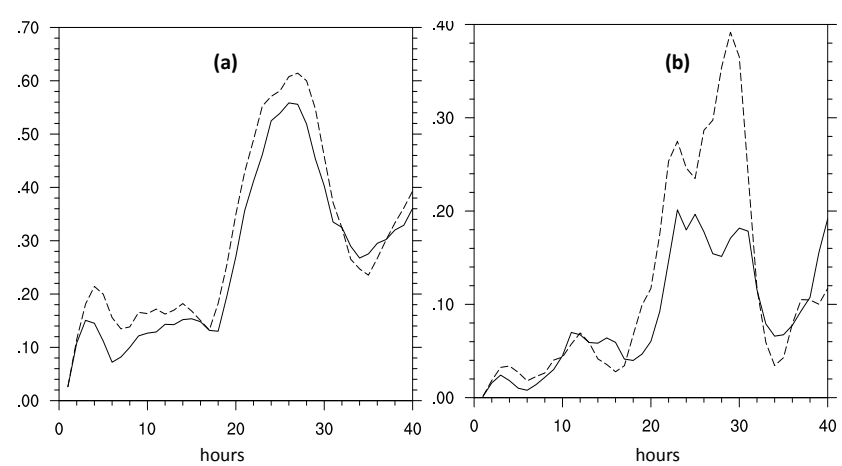

Fig. 16. Fractional coverage (a) of grid points with precipitation and precipitation rate in $\mathrm{mm}^{-1}$ (b) from simulation over large domain $(d x=10 \mathrm{~km})$ averaged over are D2. The solid line indicates run without fires, dashed line is for the runs with fires. Results include both resolved and non-resolved precipitation.

Interpretation of Fig. 15 has to be somewhat tentative, since the location of the cloud systems is slightly different, which is why we averaged results 5 points into and out of the cross section. Convection appears much stronger for the runs with 

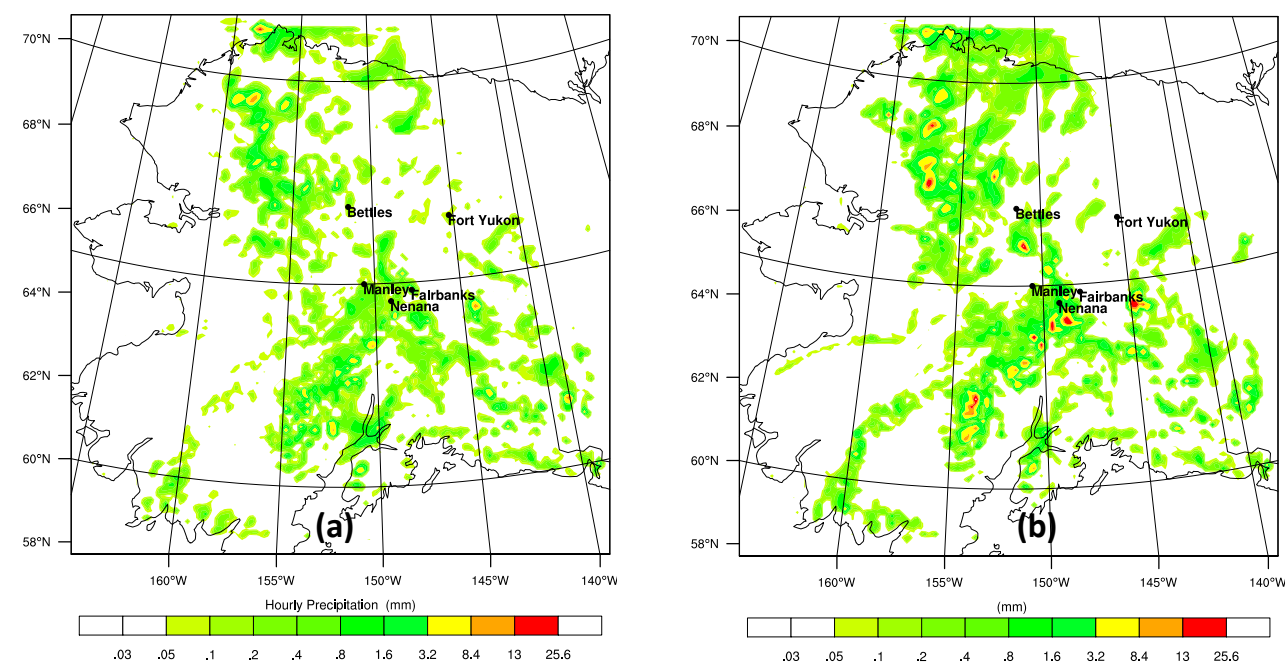

Fig. 17. Total hourly precipitation accumulation from 03:00 UTC to 04:00 UTC on 4 July 2004 as simulated over domain D1 without the effect of fires (a) and including the effect of fires (b).

fires, with stronger updraft velocities, and higher cloud- and rainwater concentrations, but also stronger downdraft outflow. Only in the anvil and in newly forming convection ahead of the system did we find higher cloud water/ice mixing ratios in the runs without fires. Previous studies (Khain et al., 2008; Han, 2010; Lim and Hong, 2010; Ntelekos et al., 2009) have shown that the aerosol cloud microphysics interactions in convective clouds are highly complex and nonlinear. Increased $\mathrm{CCN}$ numbers will increase condensation production as well as evaporation (Khain et al., 2008; Khain, 2009). Whether the precipitation that reaches the ground is more intense may depend on many factors, such as environmental humidity or shear. For our scenario additional complications are introduced through the aerosol radiation interaction leading to a change in atmospheric stability (usually an increase in CAPE in cloud free regions ahead of the convection), as well as chemical processes leading to formation and scavenging of aerosols.

Finally we take a look at domain D1. At 10-km resolution we used a convective parameterization that is based on the Grell-Devenyi (2002) approach. However, the original scheme was modified to include a flag to allow for the spreading of the subsidence to neighboring grid points. The new scheme also included neighboring grid points in determining the forcing for the convection, which make this scheme more suited for higher resolution when this flag is turned on. At this time, aerosol effects were not included in this parameterization, so that the indirect effect is produced only through the interaction of aerosols with the resolved scale cloud microphysics. In Fig. 16 we again show fractional coverage and domain-averaged total precipitation rates averaged over domain D2, but from the coarser resolution simulation (part of D1). Qualitatively, the results are somewhat similar to the cloud-resolving simulation for domain D2. Fractional coverage is somewhat higher for the runs with fires almost throughout the simulation, except for the morning of 4 July, where both fractional coverage and domain-averaged precipitation were smaller for the runs with fires. However, compared to domain $\mathrm{D} 2$, the increase in precipitation in the afternoon and evening was much more pronounced for domain D1. An example is shown in Fig. 17, displaying 1-h precipitation ending at 04:00 UTC 4 July. Both resolved and nonresolved precipitation (not shown here) showed significantly increased precipitation rates during afternoon and evening hours. This points out even more the role that the radiative interaction played in the increase in precipitation in the afternoon through increasing CAPE, since there is no aerosol indirect effect parameterized in this convective parameterization.

\section{Conclusions}

A plume rise algorithm for wildfires was successfully added to WRF-Chem. Biomass burning emissions were estimated using a biomass burning emissions model which can be based on near real-time remote sensing fire products or historic fire data to determine fire emissions and plume rise characteristics (Freitas et al., 2005, 2007; Longo et al., 2010). Fire emissions were updated as they became available, and were spatially and temporally distributed according to the fire count locations obtained by remote sensing. A 1-D time dependent cloud model was then used in WRF-Chem to estimate injection heights as well as the final emission rates. This wildfire algorithm was then applied to look at the impact of intense wildfires on weather forecasts.

In general, a strong direct effect was apparent during the daytime. Interaction of the aerosols with atmospheric radiation through scattering and absorption was very signif- 
icant in and just above the boundary layer, coinciding with the largest aerosol concentrations. In cloud-free areas this led to somewhat cooler surface temperatures. The warming above the surface layers then was causing a shallower and moister boundary layer as well as slightly increased CAPE in the clear areas. The impact of the interaction of aerosols with cloud microphysics in the presence of intense, nearby wildfires may be more difficult to categorize, since the radiative impacts cannot be completely excluded. In our studies, the initial impact of the smoke appears to decrease the precipitation (coverage and intensity), but increase the cloudwater mixing ratio and droplet numbers. This seems especially apparent during the first $12 \mathrm{~h}$ of the integration (Alaska nighttime) when there was only a small effect from the interaction of the aerosols with atmospheric radiation, and the clouds were non-convective and low level in nature. During the afternoons, precipitation became convective, and activity increased significantly in amount and coverage when smoke from fires was considered. The stronger storms were most likely caused by both the interaction of aerosols with the atmospheric radiation as well as the interaction with the cloud microphysics.

Qualitatively, similar results were seen in the larger domain that still employs a convective parameterization. However, the afternoon increase in precipitation amounts and coverage was much more pronounced. This difference in behaviour points out even more the importance of the radiative impact for our simulations.

While the improved simulation of the sounding for our case study is encouraging and a focus on online integrated systems may be timely even for Numerical Weather Prediction (NWP) models, much more research and discussion may be necessary for NWP (see also discussion in Grell and Baklanov, 2011). Additionally, better and more complete representations of physical and chemical processes and interactions in both air quality and weather prediction models are needed. The model complexity in our study is already significantly increased compared to models commonly used in operational environments, yet we feel it still requires a more complete representation of the processes involved.

Acknowledgements. This work has been supported by a grant of HPC resources from the Arctic Region Supercomputing Center (ARSC) at the University of Alaska Fairbanks (UAF) as part of the Department of Defense High Performance Computing Modernization Program, and also by the Geophysical Institute of the University of Alaska Fairbanks. We specifically would like to thank Greg Newby and Anton Kulchitsky from ARSC, and Kevin Engle from the UAF Geographic Information Network of Alaska for their support. Additionally we would like to thank to thank Richard Easter (PNNL) for extending the cloud-aerosol interaction process to the MADE/SORGAM aerosol model, John Brown for providing an internal review, and Ann Reiser for editorial assistance.

Edited by: J. Brandt

\section{References}

Abdul-Razzak, H. and Ghan, S. J.: A parameterization of aerosol activation, 2, Multiple aerosol types, J. Geophys. Res., 105, 6837-6844, 2000.

Abdul-Razzak, H. and Ghan, S. J.: A Parameterization of Aerosol Activation. 3. Sectional Representation, J. Geophys. Res., 107, 4026, doi:10.1029/2001JD000483, 2002.

Ackermann, I. J., Hass, H., Memmesheimer, M., Ebel, A., Binkowski, F. S., and Shankar, U.: Modal aerosol dynamics model for Europe: Development and first applications, Atmos. Environ., 32, 2981-2999, 1998.

Andreae, M. and Merlet, P.: Emission of trace gases and aerosols from biomass burning, Glob. Biogeochem. Cy., 15(4), 955-966, 2001.

Barnard, J. C., Fast, J. D., Paredes-Miranda, G., Arnott, W. P., and Laskin, A.: Technical Note: Evaluation of the WRF-Chem "Aerosol Chemical to Aerosol Optical Properties" Module using data from the MILAGRO campaign, Atmos. Chem. Phys., 10, 7325-7340, doi:10.5194/acp-10-7325-2010, 2010.

Belward, A.: The IGBP-DIS global $1 \mathrm{~km}$ land cover data set (DISCover)-proposal and implementation plans, IGBP-DIS Working Paper No. 13, Toulouse, France, 1996.

Chapman, E. G., Gustafson Jr., W. I., Easter, R. C., Barnard, J. C., Ghan, S. J., Pekour, M. S., and Fast, J. D.: Coupling aerosolcloud-radiative processes in the WRF-Chem model: Investigating the radiative impact of elevated point sources, Atmos. Chem. Phys., 9, 945-964, doi:10.5194/acp-9-945-2009, 2009.

Chen, F. and Dudhia, J.: Coupling an advanced landsurface/hydrology model with the Penn State/ NCAR MM5 modeling system, Part I: Model description and implementation, Mon. Weather Rev., 129, 569-585, 2001.

Easter, R. C., Ghan, S. J., Zhang, Y., Saylor, R. D., Chapman, E. G., Laulainen, N. S., Abdul-Razzak, H., Leung, L. R., Bian, X., and Zaveri, R. A.: MIRAGE: Model Description and Evaluation of Aerosols and Trace Gases, J. Geophys. Res., 109, D20210, doi:10.1029/2004JD004571, 2004.

Fahey, K. M. and Pandis, S. N.: Optimizing Model Performance: Variable Size Resolution in Cloud Chemistry Modeling, Atmos. Environ., 35, 4471-4478, 2001.

Fast, J. D., Gustafson, W. I., Easter, R. C., Zaveri, R. A., Barnard, J. C., Chapman, E. G., Grell, G. A., and Peckham, S. E.: Evolution of ozone, particulates, and aerosol direct radiative forcing in the vicinity of Houston using a fully coupled meteorology, chemistry, and aerosol model, J. Geophys. Res., 111, D21305, doi:10.1029/2005JD006721, 2006.

Freitas, S. R., Longo, K. M., Silva Dias, M., Silva Dias, P., Chatfield, R., Prins, E., Artaxo, P., Grell, G., and Recuero, F.: Monitoring the transport of biomass burning emissions in South America, Environ. Fluid Mech., 5(1-2), 135-167, doi:10.1007/s10652-005-0243-7, 2005.

Freitas, S. R., Longo, K. M., and Andreae, M. O.: Impact of including the plume rise of vegetation fires in numerical simulations of associated atmospheric pollutants, Geophys. Res. Lett., 33, L17808, doi:10.1029/2006GL026608, 2006.

Freitas, S. R., Longo, K. M., Chatfield, R., Latham, D., Silva Dias, M. A. F., Andreae, M. O., Prins, E., Santos, J. C., Gielow, R., and Carvalho Jr., J. A.: Including the sub-grid scale plume rise of vegetation fires in low resolution atmospheric transport models, Atmos. Chem. Phys., 7, 3385-3398, doi:10.5194/acp-7-3385- 
2007, 2007.

Freitas, S. R., Longo, K. M., Alonso, M. F., Pirre, M., Marecal, V., Grell, G., Stockler, R., Mello, R. F., and Sánchez Gácita, M.: PREP-CHEM-SRC - 1.0: a preprocessor of trace gas and aerosol emission fields for regional and global atmospheric chemistry models, Geosci. Model Dev., 4, 419-433, doi:10.5194/gmd-4419-2011, 2011.

Fromm, M., Alfred, J., Hoppel, K., Hornstein, J., Bevilacqua, R., Shettle, E., Servranckx, R., Li, Z., and Stocks, B.: Observations of boreal forest fire smoke in the stratosphere by POAM III, SAGE II, and lidar in 1998, Geophys. Res. Lett., 27, 14071410, 2000.

Ghan, S. J. and Easter, R. C.: Impact of cloud-borne aerosol representation on aerosol direct and indirect effects, Atmos. Chem. Phys., 6, 4163-4174, doi:10.5194/acp-6-4163-2006, 2006.

Ghan, S. J., Leung, L. R., Easter, R. C. and Abdul-Razzak, H.: Prediction of Droplet Number in a General Circulation Model, J. Geophys. Res., 102, 21777-21794, 1997.

Ghan, S. J., Easter, R. C., Chapman, E. G., Abdul-Razzak, H., Zhang, Y., and Leung, L. R., Laulainen, N. S, Saylor, R. D., and Zaveri, R. A.: A Physically Based Estimate of Radiative Forcing by Anthropogenic Sulfate Aerosol, J. Geophys. Res., 106, 5279-5293, 2001a.

Ghan, S. J., Easter, R. C., Hudson, J., and Breon, F.-M.: Evaluation of Aerosol Indirect Radiative Forcing in MIRAGE, J. Geophys. Res., 106, 5317-5334, 2001b.

Giglio, L., Descloitres, J., Justice, C. O., and Kaufman, Y. J.: An enhanced contextual fire detection algorithm for MODIS, Remote Sens. Environ., 87, 273-282, 2003.

Grell, G. A. and Baklanov, A.: Integrated Modeling For Forecasting Weather And Air Quality: A Call For Fully Coupled Approaches, Atmos. Environ., doi:10.1016/j.atmosenv.2011.01.017, 2011.

Grell, G. A. and Devenyi, D.: A generalized approach to parameterizing convection combining ensemble and data assimilation techniques, Geophys. Res. Lett., 29(14), p. 38, doi:10.1029/2002GL015311, 2002.

Grell, G. A., Peckham, S. E., McKeen, S., Schmitz, R., Frost, G., Skamarock, W. C., and Eder, B.: Fully coupled "online" chemistry within the WRF model, Atmosph. Env., 39, 6957-6975, 2005.

Gustafson Jr., W. I., Chapman, E. G., Ghan, S. J., and Fast, J. D.: Impact on modeled cloud characteristics due to simplified treatment of uniform cloud condensation nuclei during NEAQS 2004, Geophys. Res. Lett., 34, L19809, doi:10.1029/GLO30021, 2007.

Han, J.-Y.: Convectively Forced Mesoscale Flows and Cloud Aerosol Interactions, PhD Dissertation, School of Earth and Environmental Sciences, Seoul National University, 2010.

Hollingsworth, A., Engelen, R. J., Textor, C., Benedetti, A., Boucher, O., Chevallier, F., Dethof, A., Elbern, H., Eskes, H., Flemming, J., Granier, C., Kaiser, J. W., Morcrette, J. J., Rayner, P., Peuch, V.-.H, Rouil, L., Schultz, M., Simmons, A., and the GEMS consortium: Toward a monitoring and forecasting system for atmospheric composition. The GEMS Project, Bull. Am. Meteorol. Soc., 89, 1147-1164, doi:10.1175/2008BAMS2355.1, 2008.

Jacobson, M. Z.: Developing, coupling, and applying a gas, aerosol, transport,and radiation model to study urban and regional air pollution, PhD. Dissertation, Dept. of Atmospheric Sciences, UCLA, 436 pp., 1994.
Jacobson, M. Z.: Development and application of a new air pollution modeling system, Part II: Aerosol module structure and design, Atmos. Environ., 31A, 131-144, 1997a.

Jacobson, M. Z.: Development and application of a new air pollution modeling system, Part III: Aerosol-phase simulations, Atmos. Environ., 31A, 587-608, 1997b.

Janjic, Z. I.: Nonsingular Implementation of the Mellor-Yamada Level 2.5 Scheme in the NCEP Meso model, NCEP Office Note, No. 437, 61 pp., 2002.

Justice, C. O., Giglio, L., Korontzi, S., Owens, J., Morisette, J., Roy, D., Descloitres, J., Alleaume, S., Petitcolin, F., and Kaufman, Y.: The MODIS fire products, Remote Sens. Environ., 83, 244-262, 2002.

Khain, A. P.: Notes on state-of-the-art investigations of aerosol effects on precipitation: a critical review, Environ. Res. Lett., 4, 015004, doi:10.1088/1748-9326/4/1/015004, 2009.

Khain, A. P., BenMoshe, N., and Pokrovsky, A.: Factors determining the impact of aerosols on surface precipitation from clouds: An attempt at classification, J. Atmos. Sci., 65, 1721-1748, 2008.

Liu, Y., Daum, P. H., and McGraw, R. L.: Size Truncation Effect, Threshold Behavior, and a New Type of Autoconversion Parameterization, Geophys. Res. Lett., 32, L11811, doi:10.1029/2005GL022636, 2005.

Lim, K. S. and Hong, S.-Y.: Development of an Effective DoubleMoment Cloud Microphysics Scheme with Prognostic Cloud Condensation Nuclei (CCN) for Weather and Climate Models, Mon. Weather Rev., 138, 1587-1612, 2010.

Lin, Y.-L., Farley, R. D., and Orville, H. D.: Bulk parameterization of the snow field in a cloud model, J. Climate Appl. Meteor., 22, 1065-1092, 1983.

Longo, K. M., Freitas, S. R., Andreae, M. O., Setzer, A., Prins, E., and Artaxo, P.: The Coupled Aerosol and Tracer Transport model to the Brazilian developments on the Regional Atmospheric Modeling System (CATT-BRAMS) - Part 2: Model sensitivity to the biomass burning inventories, Atmos. Chem. Phys., 10, 5785-5795, doi:10.5194/acp-10-5785-2010, 2010.

McKeen, S. A., Wotawa, G., Parrish, D. D., Holloway, J. S., Buhr, M. P., Hübler, G., fehesenfeld, F. C., and Meagher, J. F.: Ozone production from Canadian wildfires during June and July of 1995, J. Geophys. Res., 107(D14), 4192, doi:10.1029/2001JD000697, 2002.

Ntelekos, A., Smith, J. A., Donner, L., Fast, J. D., Chapman, E. G., Gustafson Jr., W. I., and Krajewski, W. F.: Effect of aerosols on intense convective precipitation in the northeastern US, Q. J. Roy. Meteor. Soc., 135, 1367-1391, 2009.

Olson, J. S., Watts, J. A., and Allison, L. J.: Major World Ecosystem Complexes Ranked by Carbon in Live Vegetation: A Database (revised November 2000), NDP-017, available at: http://cdiac. esd.ornl.gov/ndps/ndp017.html (last access: 30 May 2011), Carbon Dioxide Information Analysis Center, Oak Ridge National Laboratory, Oak Ridge, Tennessee, USA, 2000.

Petters, M. D. and Kreidenweis, S. M.: A single parameter representation of hygroscopic growth and cloud condensation nucleus activity, Atmos. Chem. Phys., 7, 1961-1971, doi:10.5194/acp-71961-2007, 2007.

Prins, E., Feltz, J., Menzel, W., and Ward, D.: An overview of GOES-8 diurnal fire and smoke results for SCAR-uuand 1995 fire season in South America, J. Geophys. Res., 103(D24), 31821-31835, 1998. 
Schell, B., Ackermann, I. J., Hass, H., Binkowski, F. S., and Ebel, A.: Modeling the formation of secondary organic aerosol within a comprehensive air quality modeling system, J. Geophys. Res., 106, 28275-28293, 2001.

Seiler, W. and Crutzen, P. J.: Estimates of gross and net fluxes of carbon between the biosphere and the atmosphere from biomass burning, Climatic Change, 2, 207-247, 1980.

Sestini, M., Reimer, E., Valeriano, D., Alvalá, R., Mello, E., Chan, C., and Nobre, C.: Mapa de cobertura da terra da Amazônia legal para uso em modelos meteorológicos, Anais XI Simpósio Brasileiro de Sensoriamento Remoto, 2901-2906, 2003.

Setzer, A. and Pereira, M.: Amazonia biomass burnings in 1987 and an estimate of their tropospheric emissions, Ambio, 20, 19-22, 1991.

Skamarock, W. C., Klemp, J. B., Dudhia, J., Gill, D. O., Barker, D. M., Wang, W., and Powers, J. G.: A description of the advanced research WRF version 2, NCAR Technical Note, NCAR/TN468+STR, 8 pp., 2005.
Stockwell, W. R., Kirchner, F., Kuhn, M., and Seefeld, S.: A new mechanism for regional atmopheric modeling, J. Geophys. Res., 102, 25874-25879, 1997.

Ward, E., Susott, R., Kaufman, J., Babbit, R., Cummings, D., Dias, B., Holben, B., Kaufman, Y., Rasmussen, R., and Setzer, A.: Smoke and fire characteristics for cerrado and deforestation burns in Brazil: BASE-B Experiment, J. Geophys. Res., 97(D13), 14601-14619, 1992.

Zhang, Y., Easter, R. C., Ghan, S. J., and Abdul-Razzak, H.: Impact of Aerosol Size Representation on Modeling Aerosol-Cloud Interactions, J. Geophys. Res., 107, 4558, doi:10.1029/2001JD001549, 2002. 